\title{
Medical Students' Satisfaction Regarding Blended Learning during COVID-19 Pandemic
}

\author{
Lamiaa Lotfy El-Hawy, Khaldon Abosnenah Alssarat*, \\ Shahira Ramsis Dimetry, Marwa Bayomi Awad Allah \\ Department of Public Health and Community Medicine, Faculty of Medicine, Zagazig University, Egypt \\ *Corresponding Author: Khaldon Abosnenah Alssarat, Email: Kh.Khaldoun.Kk@gmail.com
}

\begin{abstract}
Background: The realization of the profession's role in both of global and personal concept affected the self-identification among 2020 medical students. COVID-19 pandemic can hinder, accelerate, or change medical students' professional identity formation. Objective: To assess the level of satisfaction about blended learning among undergraduate medical students at Zagazig University and to determine challenges, which face the medical students during blended learning education in Faculty of Medicine. Patients and Methods: This cross-sectional study was performed during the period from September 2020 to July 2021 at Zagazig University, Egypt. This research included 277 undergraduate medical students. Results: The current study reported that interaction satisfaction score ranged from 18 to 53 with median 37 and $53.1 \%$ of students reported high satisfaction with interaction domain. There was statistically significant correlation between total satisfaction score and both age and technology barrier. There was statistically non-significant correlation between total satisfaction score and communication barrier. Conclusion: The results show that the majority of our sample students were highly satisfied with blended learning and reported low barriers to e-learning. Students still prefer face-to-face courses despite their satisfaction with their grades and performance in blended learning courses.
\end{abstract}

Keywords: Blended learning, COVID-19, Satisfaction grading.

\section{INTRODUCTION}

The medical studies choice based on different factors, a previous study identified three domains; humanitarian, scientific, and societal (1). Another study reported that scientific and selfless and scientific reasons are the major purposes for medical career choosing ${ }^{(2)}$. Narayanasamy et al. reported other factors that affect medicine enrollment: professional calling, personal growth, professional concerns factor, and personal concerns ${ }^{(3)}$. Regarding COVID-19, this pandemic caused obstacles worldwide, and healthcare providers at the summit of this extraordinary situation ${ }^{(4,5)}$.

The realization of the profession's role in both of global and personal concept affected the selfidentification among 2020 medical students. COVID-19 pandemic can hinder, accelerate, or change medical students' professional identity formation (6). A study conducted on first-year medical students in the USA reported that $30 \%$ of students were interested about their professional or academic futures ${ }^{(7)}$. The internal and external stimulation associates positively with professional specification ${ }^{(8)}$. Chandratre also figured out the elevated obstacles in professional character formation in medical students ${ }^{(9)}$. After university enrollment, the educational process of the students is mainly affected by their passion to study. Regarding the social-cognitive, student's educational motifs is the interaction between the student's responsiveness towards the educational environment, environmental factors, and learning behavior ${ }^{(5)}$.

The transmission of the learning process toward the virtual learning had a significant effect on medical learning. Indeed, this virtual instead of in situ learning reduced student's motifs. During COVID-19 pandemic, the distraction reduced student's motivation toward learning ${ }^{(10)}$. Besides the medical students, the pandemic also, had a significant effect on lives worldwide ${ }^{(\mathbf{1 1})}$. Many studied identified the negative effects of the pandemic on the psychological aspects of students causing depression, anxiety, post-traumatic stress disorder, and other stress symptoms ${ }^{(12)}$.

The current study was performed to assess the level of satisfaction about blended learning among undergraduate medical students during clinical and preclinical phases in the Faculty of Medicine, Zagazig University. Also to compare between level of satisfaction among students in preclinical and clinical phases, with determining associated risk factors affecting the level of satisfaction among students and challenges, which face the medical students during blended learning education.

\section{PATIENTS AND METHODS}

This cross-sectional study was performed during the period from September 2020 to July 2021 at Faculty of Medicine, Zagazig University. Assuming the proportion of the students adapted the blended learning was $75 \%$ and the total number of students was (6773) students. At 95\% CI and size effect $=1$, the estimated sample was (277) students by using Epi program. By stratified sampling technique students were divided into two strata (preclinical and clinical stages), then from each stratum by cluster random method, the desired sample was obtained, taking proportional allocation in consideration.

\section{Ethical consent:}

An approval of the study was obtained from Zagazig University Academic and Ethical Committee. Every 
participant signed an informed written consent for acceptance of participation in the study. This work has been carried out in accordance with The Code of Ethics of the World Medical Association (Declaration of Helsinki) for studies involving humans.

Inclusion Criteria: Undergraduate medical students, from first to fifth grades, both sexes.

Exclusion Criteria: Students with mental or psychological disorders, foreigner students, and students who did not engage in the blended learning process.

\section{Operational Design: \\ Pilot study:}

Before start of the study, the questionnaire was pre-tested on 10 students, not included in final analysis, to evaluate applicability of the questionnaire, ensure that the wording, format, length, and sequencing of questions are appropriate. The necessary modifications were done then the questionnaire was tested for validity and reliability.

\section{Data collection:}

Student visits and interviews took place during the college's official attendance days, depending on the presence of students on the college campus. The average time that students took to fill out the questionnaire ranged from fifteen to twenty minutes.

Tools: A survey form was applied to the participants, which had four sections:

First section: Sociodemographic characteristics were assessed by questionnaire ${ }^{(\mathbf{1 3})}$.

Second section: Student Satisfaction Survey Form (SSSF), which consisted of 39 items on a 5-point Likert scale, ranging from 1 (strongly disagree) to 5 (strongly agree) for positive items and from 1 (strongly agree) to 5 (strongly disagree) for negative items ${ }^{(14)}$, and consisted of (5 domains): (1) Interaction, consisted of (13 items). (2) Instruction, consisted of (12 items). (3) Instructors, consisted of (5 items). (4) Class management (course), consisted of (3 items). (5) Technology, consisted of (6 items).

\section{Third section:}

Opinions of medical students regarding the barriers to E-learning during COVID-19 pandemic by answering specific questions using a 5-point Likert scale ranging from 1 (strongly agree) to 5 (strongly disagree) ${ }^{(15)}$, and consisted of two elements: (1) Technical and equipment barriers consisted of (16 items). (2) Communication and personnel barriers, consisted of (11 items).

Fourth section: Which included two questions: (1) Are you opposed to blended learning as an education system during the COVID-19 pandemic; yes or no, if yes why?

(2) What are your suggestions for a better educational system in light of the COVID-19 pandemic?

\section{Data Management:}

\section{(a) Scoring:}

First section: Structured questionnaire used to collect personal data such as gender, academic year, and social class. The total score of Socioeconomic Status (SES) was 48 and indicated as: High level ranged from 33.6 to 48 , ( $\geq$ $70 \%$ ). Middle level ranged from 19.2 to $<33.6$, (40\% to < $70 \%)$. Low level less than $19.2,(<40 \%)^{(13)}$.
Second section: Structured questionnaire that was used to assess students' satisfaction level, number of questions of survey 39 items ${ }^{(\mathbf{1 4})}$, total score of each domain was classified as high and low based on the median: Total score for interaction domain was $(13 \times 5=65)$. Interaction satisfaction score ranged from (18-53); was considered high $\geq 37$, low $<37$. Total score for instruction domain was $(12 \times 5=60)$. Instruction satisfaction score ranged from (18-53); was considered high $\geq 39$, low $<39$. Total score for instructor domain was $(5 \times 5=25)$. Instructor satisfaction score ranged from (5-25); was considered high $\geq 16$, low $<16$. Total score for course management was $(3 \times 5=15)$. Course management satisfaction score ranged from (3-15); was considered high $\geq 9$, low $<9$. Total score for technology domain was $(6 \times 5=30)$. Technology satisfaction score ranged from (8-30); was considered high $\geq 21$, low $<21$.

Third section: Structured questionnaire that was used to assess perception of medical students regarding the barriers to E-learning during COVID-19 pandemic, number of questions of was survey 27 items ${ }^{(\mathbf{1 5})}$, total score of each domain was classified as high and low based on the median: Total score of technical domains $(16 \times 5=80)$. Perception of technology barrier score ranged from (2163 ); was considered high $\geq 41$, low $<41$. Total score of communication domain $(11$ x $5=55)$. Perception of communication barrier score ranged from (11-47); was considered high $\geq 25$, low $<25$.

\section{Statistical analysis}

Data analysis was performed using the software SPSS (Statistical Package for the Social Sciences) version 20. Quantitative variables were described using their means, standard deviations, medians, and ranges. Categorical variables were described using their absolute frequencies and percentages and were compared using chi square and Fisher exact test when appropriate. For ordinal data, chi square for trend test was used. Kolmogorov-Smirnov (distribution-type) and Levene (homogeneity of variances) tests were used to verify assumptions for use in parametric tests. To compare quantitative data between two groups, independent sample $t$ test (for normally distributed data) was used. Spearman rank correlation coefficient was used to determine direction and strength of correlation between two quantitative variables (where one of them or both are not normally distributed). The level statistical significance was set at $\mathrm{P}<0.05$. Highly significant difference was present if $\mathrm{p} \leq 0.001$.

\section{RESULTS}

The current study reported a significant correlation between satisfaction with interaction domain as regard age (significantly higher in those with higher age), phase (clinical phase significantly had high satisfaction by 2.67 times preclinical phase), academic year (students in fourth and fifth year were significantly protected against higher satisfaction than the rest of academic years), and social class (students with high social class significantly increased satisfaction by 1.86 folds as those with medium social class) (Table 1). 
https://ejhm.journals.ekb.eg/

Table (1): Association between satisfaction with interaction domain and demographic data of the studied patients

\begin{tabular}{|c|c|c|c|c|}
\hline \multirow[t]{3}{*}{ Parameter } & \multicolumn{2}{|c|}{ Interaction } & \multirow{3}{*}{$\mathbf{P}$} & \multirow[t]{3}{*}{ COR $(95 \% \mathrm{CI})$} \\
\hline & Low & High & & \\
\hline & $\mathrm{N}=130(\%)$ & $\mathrm{N}=147(\%)$ & & \\
\hline $\begin{array}{l}\text { Age (year): } \\
\text { Mean } \pm \text { SD }\end{array}$ & $20.35 \pm 1.61$ & $20.94 \pm 1.62$ & $0.003 *$ & \\
\hline $\begin{array}{l}\text { Gender: } \\
\text { Male } \\
\text { Female }\end{array}$ & $\begin{array}{l}64(47.4) \\
66(46.5)\end{array}$ & $\begin{array}{l}71(52.6) \\
76(53.5)\end{array}$ & 0.877 & $1.04(0.65-1.66)$ \\
\hline $\begin{array}{l}\text { Academic year: } \\
\text { First } \\
\text { Second } \\
\text { Third } \\
\text { Fourth } \\
\text { Fifth }\end{array}$ & $\begin{array}{l}33(56.9) \\
38(63.3) \\
26(46.4) \\
16(28.6) \\
17(36.2)\end{array}$ & $\begin{array}{l}25(43.1) \\
22(36.7) \\
30(53.6) \\
40(71.4) \\
30(63.8)\end{array}$ & $<0.001 * *$ & $\begin{array}{l}1 \text { (reference) } \\
1.31(0.63-2.74) \\
0.66(0.32-1.37) \\
0.3(0.14-0.66) \\
0.43(0.19-0.95)\end{array}$ \\
\hline $\begin{array}{l}\text { Academic phase: } \\
\text { Preclinical } \\
\text { Clinical }\end{array}$ & $\begin{array}{l}97(55.7) \\
33(32)\end{array}$ & $\begin{array}{l}77(44.3) \\
70(68)\end{array}$ & $<0.001 * *$ & $2.67(1.6-4.45)^{*}$ \\
\hline $\begin{array}{l}\text { Social class: } \\
\text { Low } \\
\text { Medium } \\
\text { High }\end{array}$ & $\begin{array}{l}1(14.3) \\
33(60) \\
96(44.7)\end{array}$ & $\begin{array}{l}6(85.7) \\
22(40) \\
119(55.3)\end{array}$ & 0.519 & $\begin{array}{l}0.21(0.02-1.75) \\
1.86(1.02-3.4)^{*} \\
1 \text { (reference) }\end{array}$ \\
\hline
\end{tabular}

*: Significant, **: Highly significant

The current study reported that interaction satisfaction score ranged from 18 to 53 with median 37 and $53.1 \%$ of students reported high satisfaction with interaction domain (Figure 1).

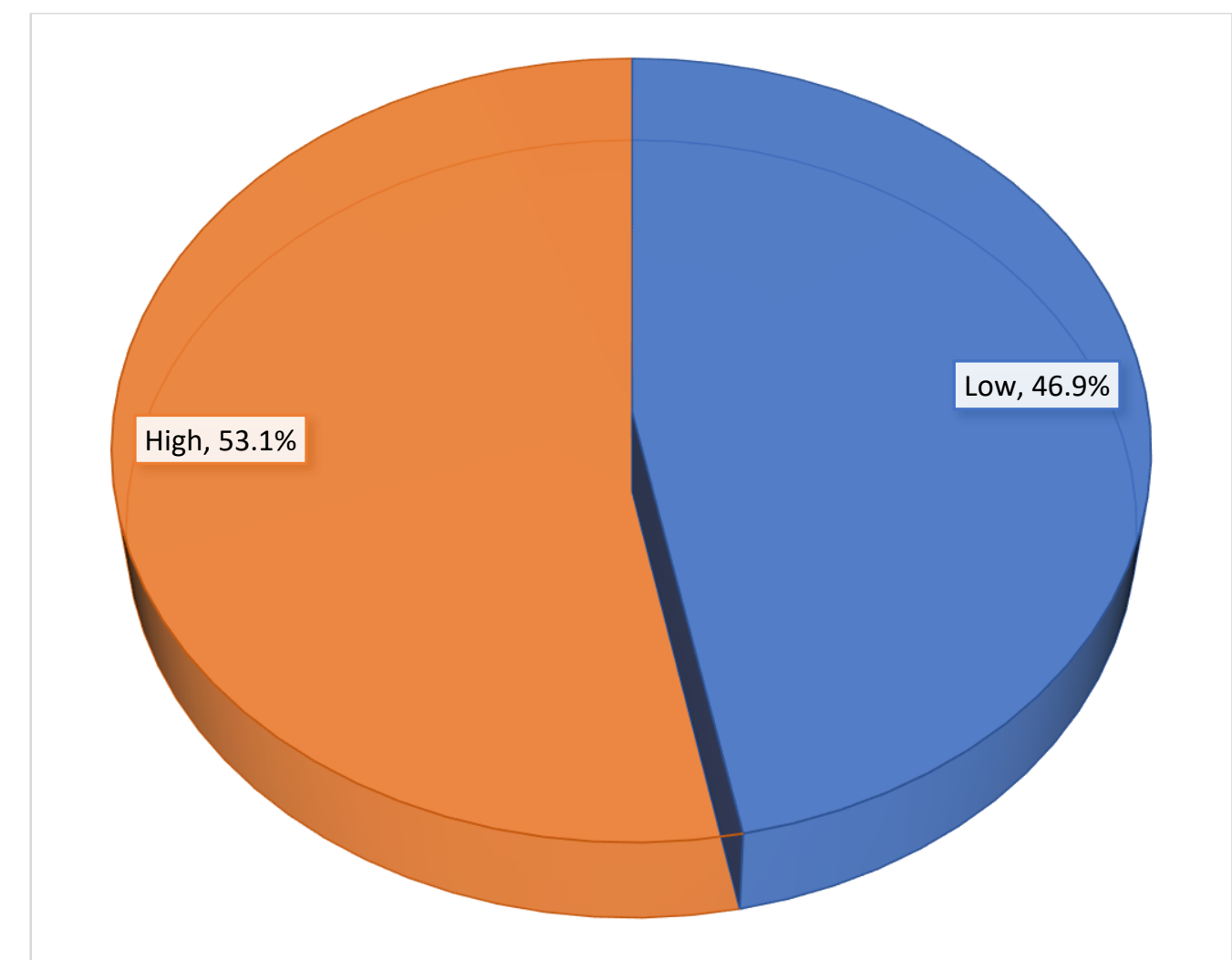

Figure (1): Pie chart showing distribution of students according to satisfaction with interaction score

Our results found that $29.2 \%$ of students agreed with that discipline is highly observed on online courses. Of the studied participants, $38.6 \%$ agreed that the lecturer always takes attendance, $34.3 \%$ disagree with that they attended video conference the same way as face-to-face classes (Table 2). 
Table (2): Distribution of the studied students according to course domain of student satisfaction survey

\begin{tabular}{|c|c|c|c|c|c|}
\hline Course & $\begin{array}{l}\text { Strongly } \\
\text { disagree } \\
\mathbf{N}(\%)\end{array}$ & $\begin{array}{l}\text { Disagree } \\
\mathrm{N}(\%)\end{array}$ & $\begin{array}{l}\text { Neutral } \\
\mathbf{N}(\%)\end{array}$ & $\begin{array}{l}\text { Agree } \\
\mathbf{N}(\%)\end{array}$ & $\begin{array}{l}\text { Strongly } \\
\text { agree } \\
\mathrm{N}(\%)\end{array}$ \\
\hline $\begin{array}{l}\text { 1-Discipline is highly observed when the } \\
\text { lecturer is on the other side of the online } \\
\text { classroom. }\end{array}$ & $45(16.2)$ & $52(18.8)$ & 49 (17.7) & $81(29.2)$ & $50(18.1)$ \\
\hline $\begin{array}{l}\text { 2-The lecturer/supervisor always takes } \\
\text { attendance. }\end{array}$ & $9(3.2)$ & $28(10.1)$ & $69(24.9)$ & $107(38.6)$ & $64(23.1)$ \\
\hline $\begin{array}{l}\text { 3-I attend videoconferencing classes the } \\
\text { same way I attend face-to-face classes. }\end{array}$ & $48(17.3)$ & $95(34.3)$ & $63(22.7)$ & $39(14.1)$ & $32(11.6)$ \\
\hline Total course score $($ Mean \pm SD) & \multicolumn{5}{|c|}{$9.51 \pm 2.5$} \\
\hline Median (range) & \multicolumn{5}{|c|}{$9(3-15)$} \\
\hline
\end{tabular}

$48.4 \%$ of students agreed with that instructor's voice was audible. Of the studied participants, $58.5 \%$ agreed with clarity of course content displayed on smart board, $49.5 \%$ agreed with that microphone was good working, $38.6 \%$ agreed about the clarity of video imaging, $34.7 \%$ agreed that technical problems were infrequent and $43.7 \%$ agreed with that technology for blended learning was reliable (Table 3).

Table (3): Distribution of the studied students according to technology domain of student satisfaction survey

\begin{tabular}{|l|l|l|l|l|l|}
\hline Technology & $\begin{array}{l}\text { Strongly } \\
\text { disagree } \\
\mathbf{N}(\%)\end{array}$ & $\begin{array}{l}\text { Disagree } \\
\mathbf{N}(\%)\end{array}$ & $\begin{array}{l}\text { Neutral } \\
\mathbf{N}(\%)\end{array}$ & $\begin{array}{l}\text { Agree } \\
\mathbf{N}(\%)\end{array}$ & $\begin{array}{l}\text { Strongly } \\
\text { agree } \\
\text { N (\%) }\end{array}$ \\
\hline 1-The instructor's voice is audible. & $7(2.5)$ & $8(2.9)$ & $44(15.9)$ & $134(48.4)$ & $84(30.3)$ \\
\hline $\begin{array}{l}\text { 2-Course content shown or displayed } \\
\text { on the smart board is clear. }\end{array}$ & $11(4)$ & $25(9)$ & $55(19.9)$ & $162(58.5)$ & $24(8.7)$ \\
\hline $\begin{array}{l}\text { 3-The microphone is in good working } \\
\text { condition. }\end{array}$ & $5(1.8)$ & $21(7.6)$ & $84(30.3)$ & $137(49.5)$ & $30(10.8)$ \\
\hline $\begin{array}{l}\text { 4-The video image is clear and } \\
\text { comprehensive when the lecturer is on } \\
\text { the other side of the online classroom. }\end{array}$ & $14(5.1)$ & $55(19.9)$ & $79(28.5)$ & $107(38.6)$ & $22(7.9)$ \\
\hline $\begin{array}{l}\text { 5-Technical problems are not } \\
\text { frequent, and they do not adversely } \\
\text { affect my understanding of the course. }\end{array}$ & $29(10.5)$ & $69(24.9)$ & $54(19.5)$ & $96(34.7)$ & $29(10.5)$ \\
\hline $\begin{array}{l}\text { 6-The technology used for blended } \\
\text { teaching is reliable. }\end{array}$ & $24(8.7)$ & $44(15.9)$ & $55(19.9)$ & $121(43.7)$ & $33(11.9)$ \\
\hline Total technology score (Mean \pm SD) & & & $20.88 \pm 3.63$ & & \\
\hline Median (range) & & & & & \\
\hline
\end{tabular}

Our results showed a significant correlation between perception of technology barrier and age (age is significantly higher in those with lower age), gender (male gender significantly associated with high perception of technology barrier), phase (preclinical phase significantly associated low perception of technology barrier), and there was a significant correlation between perception of technology barrier and academic year (students in second academic year showed low perception of technology barrier) (Table 4). 
Table (4): Association between perception technology barrier domain and demographic data of the studied patients

\begin{tabular}{|c|c|c|c|c|}
\hline \multirow[t]{3}{*}{ Parameter } & \multicolumn{3}{|c|}{ Perception of technology barrier } & \multirow{3}{*}{ COR (95\% CI) } \\
\hline & High & Low & \multirow[t]{2}{*}{$\mathbf{p}$} & \\
\hline & $\mathrm{N}=134(\%)$ & $\mathrm{N}=143(\%)$ & & \\
\hline $\begin{array}{l}\text { Age (year): } \\
\text { Mean } \pm \text { SD }\end{array}$ & $20.89 \pm 1.66$ & $20.45 \pm 1.6$ & $0.025^{*}$ & \\
\hline $\begin{array}{l}\text { Gender: } \\
\text { Male } \\
\text { Female }\end{array}$ & $\begin{array}{l}45(33.3) \\
89(62.7)\end{array}$ & $\begin{array}{l}90(66.7) \\
53(37.3)\end{array}$ & $<0.001 * *$ & $0.3(0.18-0.49)$ \\
\hline $\begin{array}{l}\text { Academic year: } \\
\text { First } \\
\text { Second } \\
\text { Third } \\
\text { Fourth } \\
\text { Fifth } \\
\end{array}$ & $\begin{array}{l}24(41.4) \\
19(31.7) \\
27(48.2) \\
37(66.1) \\
27(57.4) \\
\end{array}$ & $\begin{array}{l}34(58.6) \\
41(68.3) \\
29(51.8) \\
19(33.9) \\
20(42.6) \\
\end{array}$ & $0.002 *$ & $\begin{array}{l}1 \text { (reference) } \\
0.66(0.31-1.4) \\
1.31(0.63-2.76) \\
2.76(1.29-5.9)^{*} \\
1.91(0.88-4.17)\end{array}$ \\
\hline $\begin{array}{l}\text { Preclinical } \\
\text { Clinical }\end{array}$ & $\begin{array}{l}70(40.2) \\
64(62.1)\end{array}$ & $\begin{array}{l}104(59.8) \\
39(37.9)\end{array}$ & $<0.001 * *$ & $0.41(0.25-0.68)$ \\
\hline $\begin{array}{l}\text { Social class: } \\
\text { Low } \\
\text { Medium } \\
\text { High } \\
\end{array}$ & $\begin{array}{l}3(42.9) \\
27(49.1) \\
104(48.4) \\
\end{array}$ & $\begin{array}{l}4(57.1) \\
28(50.9) \\
111(51.6) \\
\end{array}$ & 0.926 & $\begin{array}{l}0.8(0.18-3.66) \\
1.03(0.57-1.86) \\
1 \text { (reference) }\end{array}$ \\
\hline
\end{tabular}

*: Significant, **: Highly significant

There was a statistically significant association between perception of communication barrier and both of phase (preclinical phase significantly associated with high perception of communication barrier) and social class (Table 5).

Table (5): Association between communication barrier domain and demographic data of the studied patients

\begin{tabular}{|c|c|c|c|c|}
\hline \multirow[t]{3}{*}{ Parameter } & \multicolumn{2}{|c|}{ Communication barrier } & & \multirow[t]{3}{*}{ COR $(95 \%$ CI $)$} \\
\hline & High & Low & \multirow{2}{*}{$\mathbf{P}$} & \\
\hline & $\mathrm{N}=133(\%)$ & $\mathrm{N}=144(\%)$ & & \\
\hline $\begin{array}{l}\text { Age (year): } \\
\text { Mean } \pm \text { SD }\end{array}$ & $20.74 \pm 1.61$ & $20.58 \pm 1.68$ & 0.416 & \\
\hline $\begin{array}{l}\text { Gender: } \\
\text { Male } \\
\text { Female }\end{array}$ & $\begin{array}{l}57(42.2) \\
76(53.5)\end{array}$ & $\begin{array}{l}78(57.8) \\
66(46.5)\end{array}$ & 0.06 & $0.63(0.39-1.02)$ \\
\hline $\begin{array}{l}\text { Year: } \\
\text { First } \\
\text { Second } \\
\text { Third } \\
\text { Fourth } \\
\text { Fifth }\end{array}$ & $\begin{array}{l}27(46.6) \\
24(40) \\
24(42.9) \\
36(64.3) \\
22(46.8)\end{array}$ & $\begin{array}{l}31(53.4) \\
36(60) \\
32(57.1) \\
20(35.7) \\
25(53.2)\end{array}$ & 0.21 & $\begin{array}{l}1 \text { (reference) } \\
0.77(0.37-1.59) \\
0.86(0.41-1.8) \\
2.07(0.97-4.38) \\
1.01(0.47-2.18)\end{array}$ \\
\hline $\begin{array}{l}\text { Academic phase: } \\
\text { Preclinical } \\
\text { Clinical }\end{array}$ & $\begin{array}{l}75(43.1) \\
58(56.3)\end{array}$ & $\begin{array}{l}99(56.9) \\
45(43.7)\end{array}$ & $0.033^{*}$ & $0.59(0.36-0.96)$ \\
\hline $\begin{array}{l}\text { Social class: } \\
\text { Low } \\
\text { Medium } \\
\text { High }\end{array}$ & $\begin{array}{l}1(14.3) \\
21(38.2) \\
111(51.6)\end{array}$ & $\begin{array}{l}6(85.7) \\
34(61.8) \\
104(48.4)\end{array}$ & $0.04 *$ & $\begin{array}{l}0.16(0.02-1.32) \\
0.58(0.32-1.06) \\
1 \text { (reference) }\end{array}$ \\
\hline
\end{tabular}

*: Significant

Total satisfaction score ranged from 74 to 159 with median score 121 and 52.7\% of students had high satisfaction score (Table 6). 
https://ejhm.journals.ekb.eg/

Table (6): Distribution of the studied patients according to total score of student satisfaction survey

\begin{tabular}{|l|c|c|}
\hline & $\mathbf{N = 2 7 7}$ & \% \\
\hline Total score: & & \\
Mean \pm SD & $120.61 \pm 14.08$ & \\
Median (range) & $121(74-159)$ & $47.3 \%$ \\
\hline$<\mathbf{1 2 1}$ (low) & 131 & $52.7 \%$ \\
\hline $\mathbf{1 2 1}$ (high) & 146 & \\
\hline
\end{tabular}

The study showed a significant correlation between total satisfaction score and both age and technology barrier (Table 7).

Table (7): Correlation between total satisfaction score and each of age, perception of communication and technology barriers

\begin{tabular}{|l|l|l|}
\hline & R & P \\
\hline Age & 0.136 & $0.024^{*}$ \\
\hline Technology barrier & 0.512 & $<0.001^{* *}$ \\
\hline Communication barrier & 0.091 & 0.131 \\
\hline
\end{tabular}

*: Significant, $* *$ : Highly significant

\section{DISCUSSION}

Blended learning is a coordination of instructional modalities, mainly virtual learning and face-to-face. Blended learning to be successfully implemented, it is needed to support the governments to the information and communication technology (ICT) infrastructure, institutions, assessments and curriculum reconstruction as well as great need for lecturers' training in order to elevate their skills and knowledge in ICT ${ }^{(\mathbf{1 6})}$.

The success of blended education as an educational system can be evaluated through a set of tools. the most important one of them are knowing the extent of students' satisfaction and knowing the obstacles that face them during their use of e-learning tools as one of the pillars of the blended education system ${ }^{(17)}$.

The aim of current study was measuring the satisfactory level of students regarding blended learning besides the factors affecting their satisfaction. This cross-sectional study was conducted on 277 medical students during the academic year (2020 2021) from pre-graduation stages, they were divided into the pre-clinical stage (first, second and third year) and clinical stage (fourth and fifth year). This domain consists of thirteen items, and it highlights the extent to which students are satisfied with their interaction with the elements of the blended learning system, including lecturer and students.

It is clear from the results that the higher percentage of students $(65.3 \%)$ have a higher level of concentration in the classroom than when they are in the online class, also the percentage is higher regarding interaction with lecturer in class $(68.9 \%)$ than with him in an online class, which caused by increased interruption and less discipline in online courses, it also explains the tendency of a significant proportion of students to the opinion that there is a need to visit the lecturer during official working hours.
It is evident in this study that the difference between the sexes does not significantly affect students' satisfaction or participation. In contrast to the study performed by Abou Naaj et al. ${ }^{(14)}$, on students at Ajman University, United Arab Emirates, which showed a significant difference between males' satisfaction and participation from that of females. The culture and environment shape our social reality and educational experiences ${ }^{(18)}$, which perhaps explains this difference, while in Egyptian society the participation of both sexes in the same classroom is normal, but this is not available in most societies of the Arab Gulf countries.

The current study shows that students in the clinical academic phase (fourth and fifth year) were more satisfied than those in preclinical academic phase (first, second and third year) by 2.67 times, and the grade of satisfaction with interaction domain were higher in those with higher age. This may be because students adapt as they progress in the academic years and gain experience with the blended learning system than in the early academic years, and this is agreed by the study of Al-Balas, et al. ${ }^{\left({ }^{(19)}\right.}$, in Jordan that showed that the new experience of medical students learning blended learning is unsatisfactory, while previous learning experience was significantly associated with higher student satisfaction.

In this study $(53.1 \%)$ of students reported high satisfaction with interaction domain. Regarding to course management domain, this domain which consisted of three items, the results showed that about three-quarters of students were generally satisfied with course management and noted that (51.6\%) did not agree that attending a video conferencing class was not different to a face-to-face class and this may be due to poor commitment in the online classes as in face-toface classes.

In the current study, (55.5\%) accepted that clinical skills represented a challenge in learning outcome and may not convenient for virtual learning. 
This results in agreement with the study by Ibrahim $\boldsymbol{e t}$ al. ${ }^{(15)}$, at King Abdulaziz University, which illustrates that the majority of the medical students accepted that clinical skills represented a challenge in learning outcome and may not be convenient for virtual learning and might be not suitable for e-learning, and agreed that the internet speed and quality affected their exams.

This study observed that $(72.2 \%)$ of the students think they find it difficult to understand the online class without proper guidance from the teacher. There was $(72.9 \%)$ preferred to read from print sources than electronic resources, or the internet. Warden $\boldsymbol{e t}$ al. ${ }^{(17)}$, stated that the best learning process with a controlled environment by the lecturer, which reduce online courses technical instead of the students facing problems like audio and video adjustment.

When highlighting the association between perception of technical barrier and demographic data, a significant correlation between perception of technology domain and the students' age, was higher in those with lower age and these results disagree with the results of Ibrahim et al. ${ }^{(15)}$, who reported absence of significant correlations.

There was significant association between perception of technology barrier and gender, where we found that male gender was significantly associated with high perception of technology barrier, and this finding agrees with the findings of Ibrahim $\boldsymbol{e t}$ al. ${ }^{(15)}$ and Costa et al. ${ }^{(20)}$.

Of participating students $(62.8 \%)$ agreed that e-learning courses need more time and $(70.7 \%)$ faced interruption at home while taking the e-course. $(57.4 \%)$ were not comfortable with the transition from traditional to electronic course, this results in agreement with Abo Seada and Mostafa ${ }^{(21)}$, who reported a considerable studied sample have a trouble concerning nonverbal communication, hard task and agreed that more time for e-learning course is needed. The educational environment that allows communication and social interaction lead to positive educational outcomes, also collaborative learning environment allows for teamwork and immediate feedback and enhances learner satisfaction with elearning ${ }^{(22)}$.

In this study $52 \%$ of students reported low perception of presence communication barrier domain.

To explore participating students' perspectives on whether they oppose blended learning as an education system during the COVID-19 pandemic. Only $15.5 \%$ of the student sample registered their objection to this, and among the reasons mentioned are poor internet connection and facilities, poor scheduling, and organization, and some of them refused to study at the time of the pandemic completely for safety.

When students were asked about their suggestions about the best education system suitable for the conditions of the COVID-19 pandemic, among the participating sample, sixty-five students scored their suggestions, $15.4 \%$ of them focused on giving the online sessions more time, and about $12 \%$ suggested improving communication skills, while others suggested the electronic exams, and some of them preferred to support the traditional method of education rather than including distance education in the educational process.

Finally, the majority of our sample students were highly satisfied with blended learning. In agreement with our results Abo Seada and Mostafa $^{(21)}$, Huange et al. ${ }^{(23)}$ and Franz-Vasdeki et al. ${ }^{\text {(24) }}$ agree that students' satisfaction and the success of the learning package run a parallel line, each contributing to the other. The main objective of any educational program is to be satisfied with this program, which leads to the success and continuation of the learning package because it confirms the effectiveness of the educational process and increases its efficiency.

\section{CONCLUSION}

The results show that the majority of our sample students were highly satisfied with blended learning and reported low barriers to e-learning. Students still prefer face-to-face courses despite their satisfaction with their grades and performance in blended learning courses.

Financial support and sponsorship: Nil. Conflict of interest: Nil.

\section{REFERENCES}

1. Goel S, Angeli F, Dhirar N et al. (2018): What motivates medical students to select medical studies: a systematic literature review. BMC Med Educ., 18(1):16-21.

2. Gąsiorowski J, Rudowicz E, Safranow K (2015): Motivation towards medical career choice and future career plans of Polish medical students. Adv Health Sci Educ., 20(3):709-25.

3. Narayanasamy M, Ruban A, Sankaran $P$ (2019): Factors influencing to study medicine: a survey of firstyear medical students from India. Korean J Med Educ., 31(1):61-71.

4. Shreffler J, Huecker M, Petrey J (2021): The impact of COVID-19 on healthcare worker wellness: A scoping review. West J Emerg Med., 21(5): 1-5.

5. Bolatov A, Gabbasova A, Baikanova $R$ et al. (2021): Online or blended learning: the COVID-19 pandemic and first-year medical students' academic motivation. Med Sci Educ., 21: 1-4.

6. Stetson G, Kryzhanovskaya I, Lomen-Hoerth $\mathrm{C}$ et al. (2020): Professional identity formation in disorienting times. Med Educ., 54(8):765-6.

7. Slivkoff M, Johnson C, Tackett S (2021): First-year medical student experiences adjusting to the immediate aftermath of COVID-19. Med Sci Educ., 31(2):557-64.

8. Wasityastuti W, Susani Y, Prabandari Y et al. (2018): Correlation between academic motivation and professional identity in medical students in the Faculty of Medicine of the Universitas Gadjah Mada Indonesia. Educ Médica., 19(1):23-9. 
9. Chandratre S (2020): Medical Students and COVID-19: Challenges and supportive strategies. J Med Educ Curric Dev., 7: 505-509.

10. Deshetler L, Gangadhar M, Battepati D et al. (2021): Learning on lockdown: A study on medical student wellness, coping mechanisms and motivation during the COVID-19 pandemic. Med Ed Publish., 10(1): 1-5.

11. Sahu P (2020): Closure of universities due to coronavirus disease 2019 (COVID-19): Impact on education and mental health of students and academic staff. Cureus, 12(4): $1-6$.

12. Saladino V, Algeri D, Auriemma V (2020): The psychological and social impact of Covid-19: new perspectives of well-being. Front Psychol., 11: 684-88.

13. Fahmy S, Nofal L, Shehata $S$ et al. (2015): Updating indicators for scaling the socioeconomic level of families for health research. J Egypt Public Health Assoc., 90(1):17.

14. Abou Naaj M, Nachouki M, Ankit A (2012): Evaluating student satisfaction with blended learning in a gendersegregated environment. J Inf Technol Educ Res., 11: 185200.

15. Ibrahim N, Al Raddadi R, AlDarmasi M et al. (2021): Medical students' acceptance and perceptions of e-learning during the Covid-19 closure time in King Abdulaziz University, Jeddah. J Infect Public Health, 14(1):17-23.

16. Adams D, Joo M, Sumintono B et al. (2020): Blended learning engagement in higher education institutions: a differential item functioning analysis of students' backgrounds. Malays J Learn Instr., 17(1):133-58.
17. Warden C, Stanworth J, Ren J et al. (2013): Synchronous learning best practices: An action research study. Comput Educ., 63:197-207.

18. Ting-Toomey S, Dorjee T (2018): Communicating across cultures. Second edition. New York: The Guilford Press. Guilford Publications. Pp. 464. https://www.worldcat.org/ title/communicating-across-cultures/oclc/1049910030

19. Al-Balas M, Al-Balas $\mathrm{H}$, Jaber $\mathrm{H}$ et al. (2020): Distance learning in clinical medical education amid COVID-19 pandemic in Jordan: current situation, challenges, and perspectives. BMC Med Educ., 20(1):341-45.

20. Costa A, Costa A, Olsson I (2020): Students' acceptance of e-learning approaches in Laboratory Animal Science Training. Lab Anim., 54(5):487-97.

21. Abo Seada A, Mostafa M. (2017): Students' satisfaction and barriers of E-learning course among nursing students, Mansoura University. World Journal of Nursing Sciences, 3 (3): 170-178,

22. Bolliger D, Halupa C (2012): Student perceptions of satisfaction and anxiety in an online doctoral program. Distance Educ., 33(1):81-98.

23. Huang F, Blaschke S, Lucas $H$ (2017): Beyond pilotitis: taking digital health interventions to the national level in China and Uganda. Glob Health, 13(1):49-53.

24. Franz-Vasdeki J, Pratt B, Newsome $M$ et al. (2015): Taking mHealth solutions to scale: Enabling environments and successful implementation. J Mob Technol Med., $4(1): 35-38$. 